\title{
Activated Carbon Prepared from Semi-Coke as an Effective Adsorbent for Dyes
}

\author{
Mei Dong, Huiliang Zhou*, Wanyi Liu, Chenlong He \\ State Key Laboratory of High-efficiency Coal Utilization and Green Chemical Engineering, College of Chemistry \\ and Chemical Engineering, Ningxia University, Yinchuan 750021, China
}

Received: 11 February 2018

Accepted: 15 December 2018

\begin{abstract}
Activated carbon from semi-coke (named SAC) was successfully prepared by high temperature vapor activation. As an adsorbent, its adsorption behaviors for dyes from aqueous solutions was studied. The porous texture parameters determined by $\mathrm{N}_{2}$ adsorption at $77 \mathrm{~K}$ indicated that SAC was essentially mesoporous and had a surface area of $724.9 \mathrm{~m}^{2} \mathrm{~g}^{-1}$. SEM result showed clearly that the surface of SAC was very porous. The adsorption experiment data exhibited that the adsorption capacity of SAC increased with the contact time until adsorption equilibrium. The adsorption mechanism of SAC was explored by isotherm and kinetic studies. It was found that the adsorption of dye followed the Freundlich isotherm and the pseudo first-order equation.
\end{abstract}

Keywords: semi-coke, activated carbon preparation, characterization, adsorption isotherm and kinetics, dye wastewater

\section{Introduction}

With the development of the dye industry, dye wastewater emissions have increased dramatically. The presence of dyes in untreated effluents is unfriendly to the environment, for example, coloring water bodies, disturbing the aquatic system, being chronic and acute toxicities to human beings, etc. So dye-containing wastewater requires treatment before disposal. The most common techniques for removing dyes include membrane separation $[1,2]$, advanced oxidation $[3,4]$, and biological treatment $[5,6]$, etc. However, there are certain disadvantages of these techniques such as high cost or secondary pollution. The adsorption technique is considered to be an effective method for wastewater treatment, especially with activated carbon due to its

*e-mail: 13995209835@163.com high adsorption capacity [7-12]. However, the high initial and regeneration cost of activated carbon limits its use $[13,14]$. Hence, many investigators are studying for the alternate adsorbents that are equivalent to activated carbon, but inexpensive and abundant. These include: shell [15, 16], sludge [17], slag [18], palm fruit bunch [19], and straw [20].

As the product of coal gasification at medium temperature, semi-coke is the raw material of certain industries such as ferroalloy, calcium carbide and so on. During the transportation and production process, a large amount of semi-coke powder with particle size less than $3 \mathrm{~mm}$ is produced. This powder becomes solid waste for not meeting the production process requirements. So semi-coke powder is cheap and available, and moreover it has some beneficial properties in preparation of activated carbon. As solid waste, semi-coke powder is harmful to the environment. When it is prepared to be activated carbon it becomes 
valuable material. If the adsorption properties of the activated carbon from semi-coke were better, it could be used as an adsorbent instead of common activated carbon for wastewater treatment, and the cost could be reduced. It has been reported in the literature [21] that the activated carbon was prepared from semi-coke by $\mathrm{KOH}$ activation. In this research, we explore activating semi-coke only by high-temperature vapor without pretreatment and investigate the adsorption capacity and mechanism of the activated semi-coke for removing dyes from simulated wastewater.

\section{Materials and Methods}

\section{Materials}

Semi-coke (SC) was obtained from the Tongda Semi-Coke Plant in Shenmu County in Shanxi Province. The received semi-coke was ground and separated by sieving to obtain the particles with grain diameter below $0.6 \mathrm{~mm}$.

Methyl orange(MO), Ind, was purchased from Beijing Chemical Plant.

Industrial-grade blue dye (BD) was purchased from Shanghai Jiaying Chemical Co., Ltd.

\section{Activated Carbon Preparation}

The proximate analysis of SC was done in duplicate. Thermo-gravimetric analysis (TG) (Setsys Evolution, France) was conducted from room temperature to $1000^{\circ} \mathrm{C}$ at a rate of $10^{\circ} \mathrm{C} / \mathrm{min}$ under nitrogen conditon before $850^{\circ} \mathrm{C}$ and air condition after $850^{\circ} \mathrm{C}$ in order to assess the thermostability of SC.

Physical activation was carried out for activated carbon preparation. The procedure was as follows: the sample was heated at a rate of $5^{\circ} \mathrm{C} / \mathrm{min}$ in a laboratory tubular furnace under $\mathrm{N}_{2}$ atmosphere from room temperature to $800^{\circ} \mathrm{C}$, then $\mathrm{N}_{2}$ atmosphere was switched to vapor and maintained at $800^{\circ} \mathrm{C}$ for $2 \mathrm{~h}$ to activate the sample. After that, the sample was allowed to cool down under $\mathrm{N}_{2}$ flow, then dried in an oven at $110^{\circ} \mathrm{C}$ for $12 \mathrm{~h}$. The activated sample was named SAC.

\section{Characterization of Samples}

The textural characterization of the samples before and after activation was evaluated by $\mathrm{N}_{2}$ adsorption and desorption data at $77 \mathrm{~K}$ (ASAP 2010, USA). Specific surface area of the samples was calculated according to the Brunauer-Emm-ett-Teller (BET) method, and micropore/mesopore volume and pore size distribution were determined by the Barrett-Joyner-Halenda (BJH) equations. X-ray diffraction (XRD) was conducted by using an instrument with $\mathrm{Cu} \mathrm{K} \alpha$ radiation (Dmax 2200PC, Japan) to analyze crystalline structure changes of the samples before and after activation. The images of SC and SAC were taken using scanning electron microscopy (JSM7500F, JEOL, Japan) to see pores and surface appearance changes before and after activation. Fourier transform infrared (FTIR) spectra (IRTracer-100) was used to analyze the changes of functional groups of the sample surface before and after activation and of the SAC surface before and after adsorption.

$$
\begin{gathered}
\text { Adsorption of Methyl Orange (MO) } \\
\text { and Blue Dye (BD) }
\end{gathered}
$$

The adsorption experiments were carried out in a shaker at $150 \mathrm{rpm}$ at room temperature using a $150 \mathrm{~mL}$ conical flask with cover containing $0.05 \mathrm{~g}$ (for studing adsorption kinetics) and $0.1 \mathrm{~g}$ (for studing adsorption isotherms) of investigated $\mathrm{SAC}$ and $50 \mathrm{~mL}$ of $\mathrm{MO}$ or BD solutions with concentrations between 100 and $500 \mathrm{mgL}^{-1}$ for a period of $24 \mathrm{~h}$. The original solution of the experiment was $1000 \mathrm{mgL}^{-1}$ by dissolving chemicalgrade $\mathrm{MO}$ or $\mathrm{BD}$ in distilled water. The experimental solutions with certain concentrations were obtained by diluting the original solution appropriately with distilled water. The exact initial and equilibrium solutions concentrations of $\mathrm{MO}$ and $\mathrm{BD}$ were determined by ultraviolet and visible spectrophotometry (TU-1810). The adsorption capacities of SAC for MO and BD were calculated from the equation as:

$$
q_{e}=V \times\left(C_{0}-C_{e}\right) / m
$$

...where $q_{e}$ is the equilibrium adsorption capacity of SAC (mgg $\left.{ }^{-1}\right), C_{0}$ and $C_{e}$ are initial and equilibrium concentrations of $\mathrm{MO}$ or $\mathrm{BD}\left(\mathrm{mgL}^{-1}\right), V$ is the solution volume of $\mathrm{MO}$ or $\mathrm{BD}(\mathrm{L})$ and $m$ is the $\mathrm{SAC}$ weight $(\mathrm{g})$.

\section{Results and Discussion}

Proximate analysis results of SC are given in Table 1 . The carbon content is $83.9 \%$ which means that $\mathrm{SC}$ can be activated directly without carbonization step.

Thermo-gravimetric analysis of $\mathrm{SC}$ was done using TG/DTG curves shown in Fig. 1. Two major weight losses oocurred. The first weight loss is at $60^{\circ} \mathrm{C}$, which is related to surface water. Another weight loss occurred between $600^{\circ} \mathrm{C}$ and $800^{\circ} \mathrm{C}$ in connection with the decomposition of volatiles.

\section{Textural Characteristics of Semi-Coke (SC) and SC-Based Activated Carbons (SAC)}

The nitrogen adsorption isotherm curves of SC and SAC at $77 \mathrm{~K}$ are shown in Fig. 2. In terms of IUPAC

Table 1. Proximate analysis of Semi-coke(SC).

\begin{tabular}{|c|c|c|c|c|}
\hline Sample & $\mathrm{C}_{\mathrm{fix}}(\mathrm{wt} \%)$ & $\mathrm{Ash}(\mathrm{wt} \%)$ & $\mathrm{VM}(\mathrm{wt} \%)$ & $\mathrm{W}(\mathrm{wt} \%)$ \\
\hline $\mathrm{SC}$ & 83.98 & 7.55 & 8.47 & 15 \\
\hline
\end{tabular}




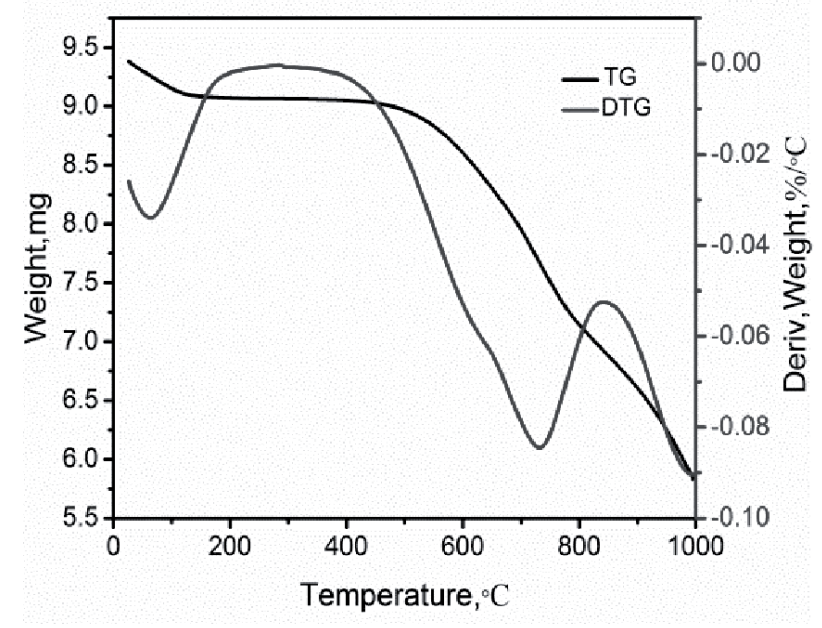

Fig. 1. Thermo-gravimetric (TG) and derivative thermogravimetric (DTG) curves of semi-coke (SC).

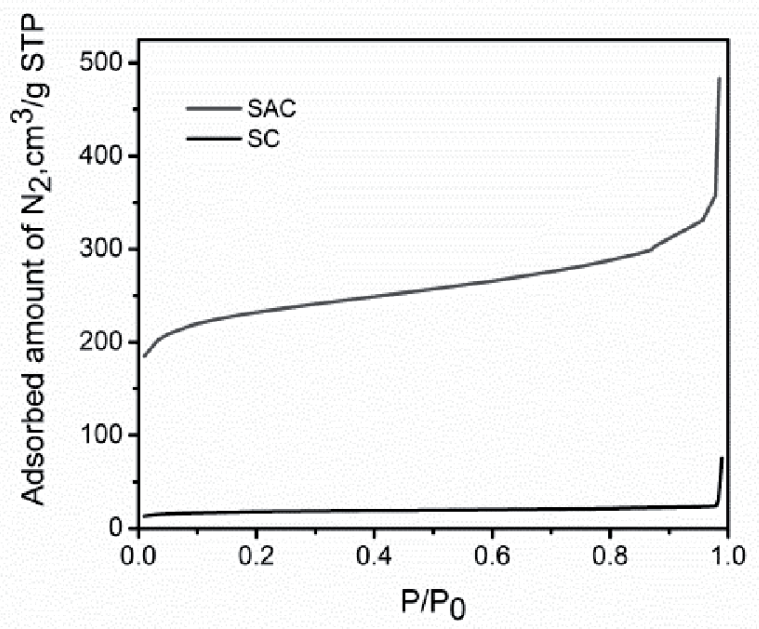

Fig. 2. Nitrogen adsorption isotherms of the samples.

classification, two of the curves stand for a type II shape, which is usually considered to represent monolayer adsorption at low pressure, while as the pressure increases the multi-layer adsorption is generated. When the pressure is quite high, the adsorption gas begins to condense into liquid phase, so the adsorption quantity rises sharply.

The porous property parameters obtained by $\mathrm{N}_{2}$ adsorption at $77 \mathrm{~K}$ in Table 2 shows that the surface area $\left(\mathrm{S}_{\mathrm{BET}}\right)$ and total pore volume $\left(\mathrm{V}_{\text {Total }}\right)$ of SAC are higher than that of $\mathrm{SC}$ due to the high temperature vapor activation process that enhanced the porous texture of a)

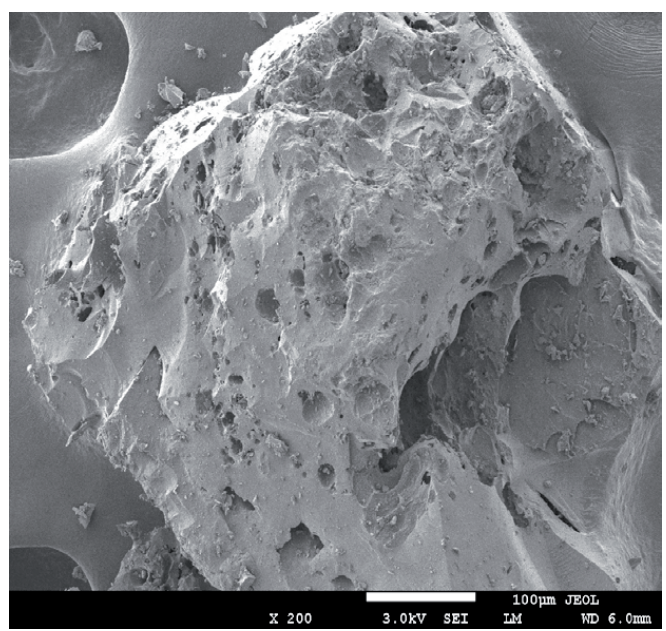

b)

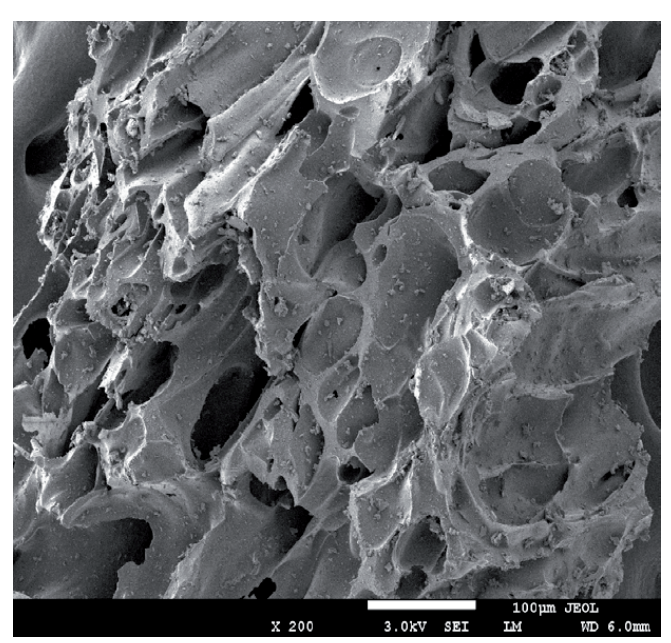

Fig. 3. SEM images of SC a) and SAC b).

SAC. $\mathrm{S}_{\mathrm{BET}}$ of SAC is $724.9 \mathrm{~m}^{2} \mathrm{~g}^{-1}$, while $\mathrm{S}_{\mathrm{BET}}$ of $\mathrm{SC}$ is only $56.3 \mathrm{~m}^{2} \mathrm{~g}^{-1}$ and $\mathrm{SAC}$ is maily mesporous.

Microstructural characterization of SC and SAC was carried out using SEM. It shows in Fig. 3b) clearly that the surface of SAC is very porous and denser compared to SC, as Fig. 3a) shows. Obviously, this is a benefit to the activation process.

FT-IR was employed to observe surface functional groups of SC and SAC, SAC after adsorption of MO and $\mathrm{BD}$ (as shown in Fig. 4). The bands correspond to four major absorption peaks of both $\mathrm{SC}$ and $\mathrm{SAC}$ that were observed and attributed to $\mathrm{O}-\mathrm{H}, \mathrm{C}-\mathrm{H}, \mathrm{C}=\mathrm{C}$ or $\mathrm{C}=\mathrm{N}, \mathrm{C}=\mathrm{O}$ stretching functional groups, and all of them were dramatically enhanced in the SAC due to the high temperature vapor activation, indicating that the surface of SC was strongly oxidized. After adsorption of $\mathrm{MO}$ or $\mathrm{BD}$, the absorption peak of SAC at $1620 \mathrm{~cm}^{-1}$

Table 2. Nitrogen adsorption results for SC and SAC.

\begin{tabular}{|c|c|c|c|c|c|c|}
\hline Sample & $\mathrm{S}_{\text {BET }}\left(\mathrm{m}^{2} / \mathrm{g}\right)$ & $\mathrm{S}_{\text {Micro }}\left(\mathrm{m}^{2} / \mathrm{g}\right)$ & $\mathrm{S}_{\text {Meso }}\left(\mathrm{m}^{2} / \mathrm{g}\right)$ & $\mathrm{V}_{\text {Total }}\left(\mathrm{cm}^{3} / \mathrm{g}\right)$ & $\mathrm{V}_{\text {Micro }}\left(\mathrm{cm}^{3} / \mathrm{g}\right)$ & $\mathrm{V}_{\text {Meso }}\left(\mathrm{cm}^{3} / \mathrm{g}\right)$ \\
\hline $\mathrm{SC}$ & 56.3203 & 28.9646 & 27.3557 & 0.116622 & 0.015758 & 0.096685 \\
\hline $\mathrm{SAC}$ & 724.9393 & 458.3668 & 228.9162 & 0.747538 & 0.242298 & 0.5017 \\
\hline
\end{tabular}




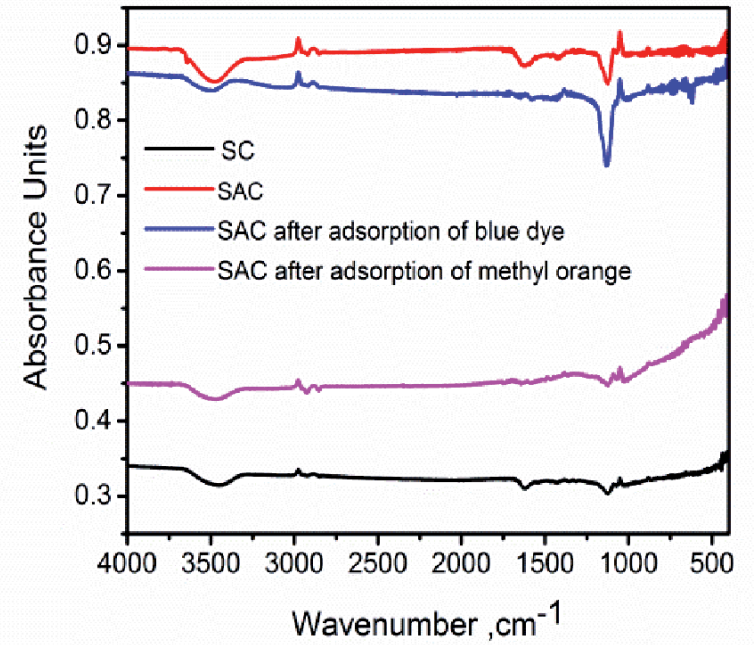

Fig. 4. FTIR spectra of SC, SAC, SAC after adsorption of blue dye and SAC after adsorption of methyl orange.

disappeared. It can be expected that the functional group had reacted with $\mathrm{BD}$ or $\mathrm{MO}$ during the adsorption process. The absorption peak at $1123 \mathrm{~cm}^{-1}$ of SAC is observed enhanced after adsorption of $\mathrm{BD}$, indicating that the $\mathrm{C}=\mathrm{O}$ functional group played a role in the adsorption process.

Fig. 5 shows XRD patterns of SC and SAC samples. Two diffraction peaks can be observed at $2 \theta=26^{\circ}$, $2 \theta=43^{\circ}$, which can be indexed to different crystal planar of carbon. Fig. 5 shows that the intensity of the diffraction of SAC became weaker than that of SC, indicating amorphous carbon with a chaotic layer of SAC redued. Besides, there are more impurity peaks in the SAC pattern than SC because of the erosion of some carbon during activation, thus the content of impurities is higher in SAC.

\section{Adsorption Behaviours}

Adsorption properties of methyl orange (MO) and blue dye (BD) with SAC are shown in Fig. 6.

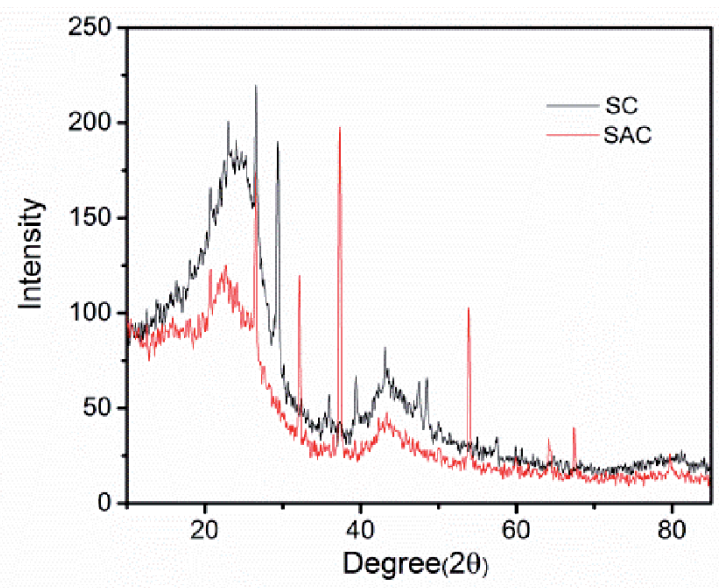

Fig. 5. XRD patterns of SC and SAC.

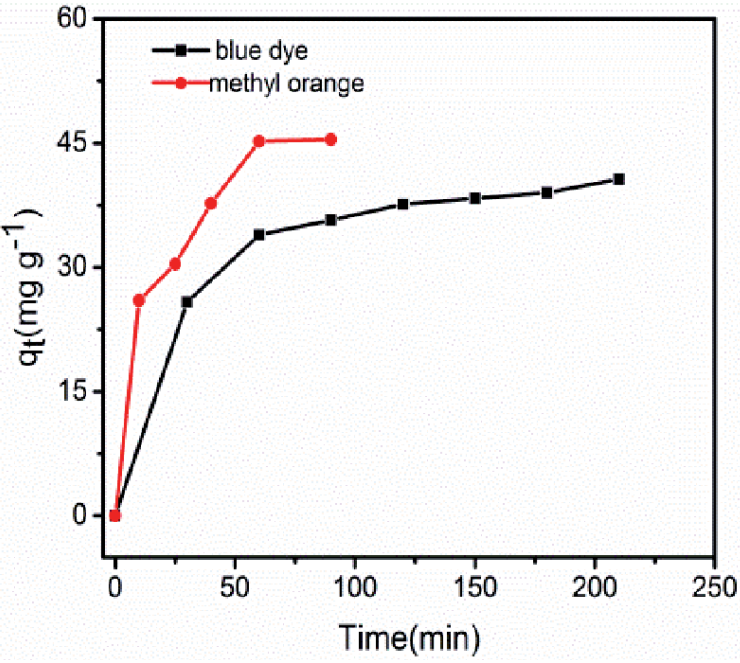

Fig. 6. $\mathrm{MO}$ and $\mathrm{BD}$ adsorption capacities with the contact time $\left(\mathrm{C}_{0}=100 \mathrm{mg} / \mathrm{L}\right.$, shaking speed $=150 \mathrm{rpm}$ and $\mathrm{m}=0.1 \mathrm{~g}$, $\mathrm{V}=50 \mathrm{~mL}$, T: room temperature).

The adsorption rate of $\mathrm{MO}$ was faster than that of $\mathrm{BD}$ with SAC perhaps duo to the molecule of the former was smaller than that of the latter, so the MO molecules
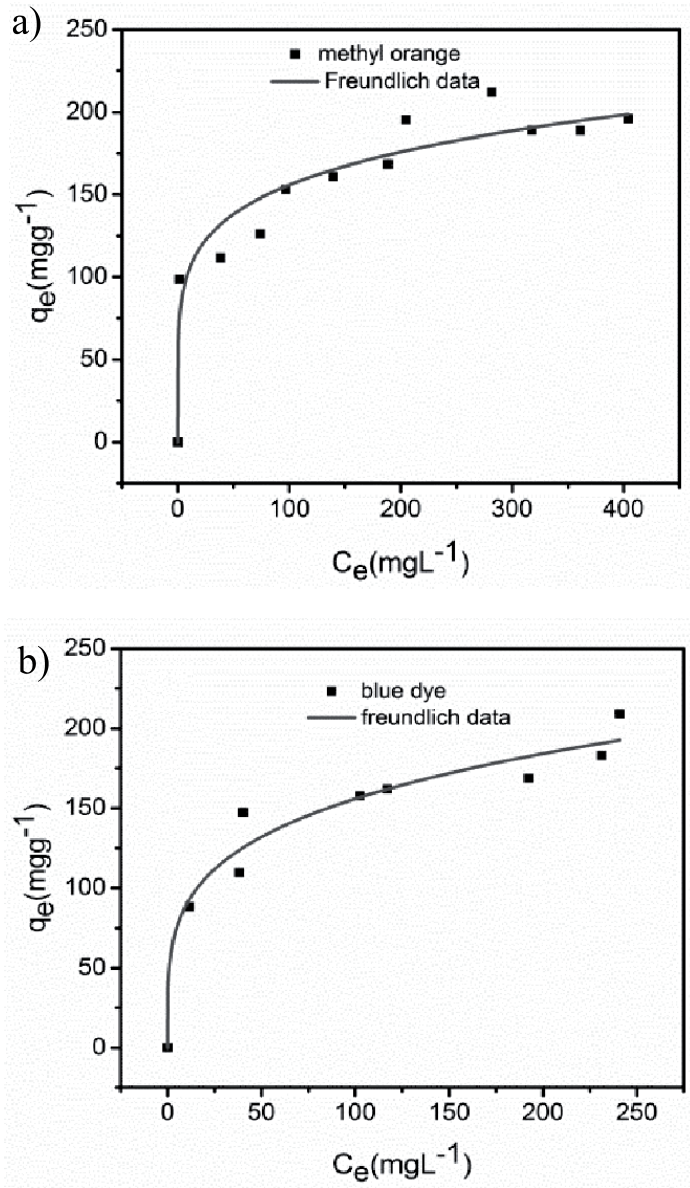

Fig. 7. Adsorption isotherms of SAC for MO a) and BD b); stirring Speed $=150 \mathrm{rpm}$ and $\mathrm{m}=0.05 \mathrm{~g}, \mathrm{~V}=50 \mathrm{~mL}$, T: room temperature. 

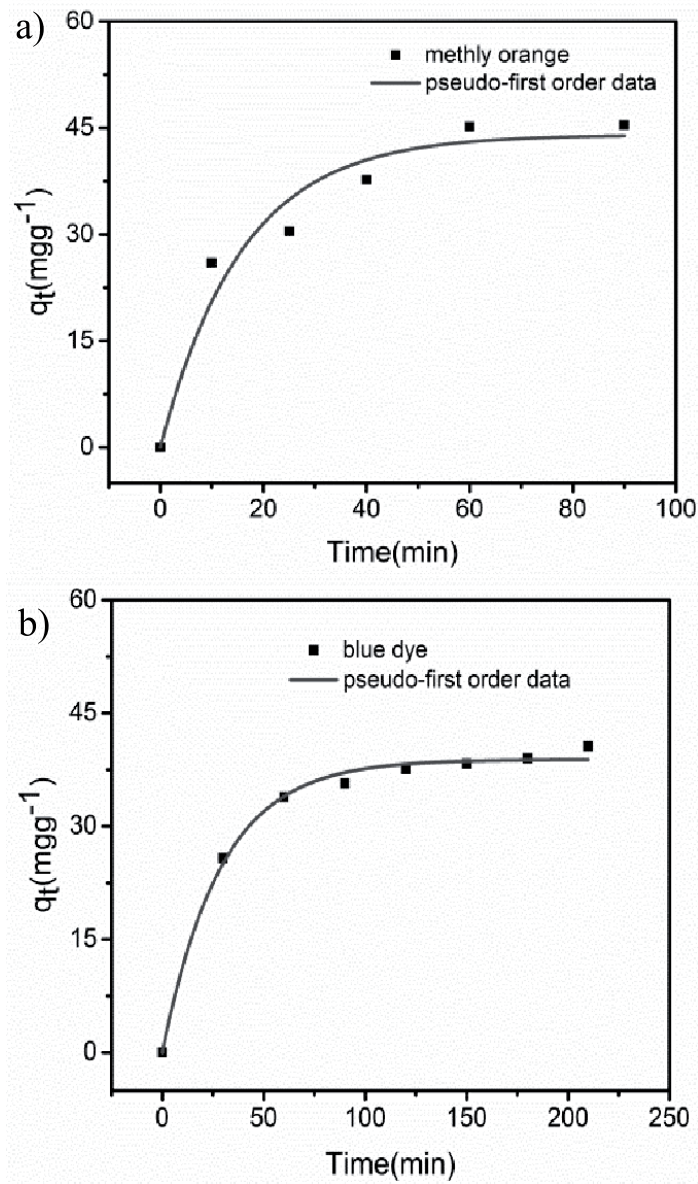

Fig. 8. Adsorption kinetics of SAC for methyl a) and orange dye b) $\mathrm{C}_{0}=100 \mathrm{mg} / \mathrm{L}$, stirring speed $=150 \mathrm{rpm}$ and $\mathrm{m}=0.1 \mathrm{~g}$, $\mathrm{V}=50 \mathrm{~mL}, \mathrm{~T}=$ room temperature.

moved faster in solution. But the maximal adsorption capacity of both was almost the same, proving that SAC had more mesopores and macropores, which agreed with BET because $\mathrm{MO}$ and $\mathrm{BD}$ are all macromolecule.
In order to further research the adsorption mechanism of SAC we studied the adsorption isotherm and kinetics. For adsorption isotherm, the Langmuir and Freundlich isotherms are two widely used ones. Fig. 7(a-b) are adsorption isotherms of $\mathrm{MO}$ and $\mathrm{BD}$ on SAC. Langmuir and Freundlich constants and correlation coefficients of $\mathrm{MO}$ and $\mathrm{BD}$ adsorption isotherms are given in Table 3. The Freundlich equation fits a little better than Langmuir with higher correlation coefficients.

Kinetics studies contribute to the investigation of adsorption dynamics mechanisms. In our study, the experimental data were analyzed by the pseudo first- and second-order models. Results are shown in Fig. 8(a-b).

Table 4 shows the kinetic parameters and correlation coefficients of the kinetic models from which we can see that, for both $\mathrm{MO}$ and $\mathrm{BD}$, the correlation coefficients described by the pseudo first-order model are somewhat lower than that of the pseudo second-order model, but the experimental qe(exp) values are close to the calculated ones. So we think the pseudo first-order model is the better fit.

\section{Conclusions}

Highly porous activated carbon was successfully prepared from solid waste semi-coke by high temperature vapor activation and applied in the adsorption of dyes from aqueous solutions. Results of SEM showed that the activated semi-coke (SAC) was more porous than the original semi-coke (SC), and BET gave the result that $\mathrm{SAC}$ had a much higher surface area than SC. In the adsorption experiment, SAC had high adsorption efficiency toward dye removal. An adsorption kinetics study demonstrated that the pseudo first-order equation could describe the adsorption process better. From adsorption isotherm data we could find that

Table 3. Langmuir and Freundlich parameters for adsorption of MO and BD by SAC.

\begin{tabular}{|c|c|c|c|c|c|c|}
\hline & \multicolumn{5}{|c|}{ Isotherm parameters } \\
\cline { 2 - 7 } & \multicolumn{3}{|c|}{ Langmuir model } & $\mathrm{K}_{\mathrm{f}}$ & $\mathrm{n}$ & $\mathrm{R}^{2}$ \\
\cline { 2 - 7 } & $\mathrm{q}_{\mathrm{m}}$ & $\mathrm{b}$ & $\mathrm{R}^{2}$ & 69.89535 & 0.17411 & 0.92795 \\
\hline $\mathrm{MO}$ & 213.17447 & 0.02796 & 0.73461 & 51.53692 & 0.24036 & 0.95508 \\
\hline $\mathrm{BD}$ & 197.47482 & 0.05254 & 0.93466 & & \\
\hline
\end{tabular}

Table 4. Kinetic parameters for MO and BD adsorption on SAC.

\begin{tabular}{|c|c|c|c|c|c|c|c|}
\hline \multirow{2}{*}{ Sample } & \multicolumn{4}{|c|}{ First-order model } & \multicolumn{4}{c|}{ Second-order model } \\
\cline { 2 - 9 } & $\mathrm{q}_{\mathrm{e}, \mathrm{exp}}$ & $\mathrm{q}_{\mathrm{e}, \mathrm{cal}}$ & $\mathrm{K}_{1}$ & $\mathrm{R}^{2}$ & $\mathrm{q}_{\mathrm{e}, \mathrm{cal}}$ & $\mathrm{K}_{2}$ & $R^{2}$ \\
\hline SAC adsorption of MO & 45.4 & 44.05287 & 0.06291 & 0.94402 & 51.24332 & 0.00159 & 0.97041 \\
\hline SAC adsorption of BD & 40.6 & 38.86566 & 0.03457 & 0.99425 & 43.89357 & 0.00113 & 0.99816 \\
\hline
\end{tabular}


the Freundlich equation fits a little better than Langmuir with higher correlation coefficients.

The preparation method to make semi-coke, the solid waste, to be valuable adsorbent is simple and effective, but further work is needed in order to make the activated carbon much better.

\section{Acknowledgements}

This work was supported by the national First-Rate Discipline Construction Project of Ningxia (chemical engineering and technology) (NXYLXK2017A04).

\section{Conflict of Interest}

The authors declare no conflict of interest.

\section{References}

1. BABU J., MURTHY Z.V.P. Treatment of textile dyes containing wastewaters with PES/PVA thin film composite nanofiltration membranes. Separation and Purification Technology, 183, 72, 2017.

2. LIU M.H., CHEN Q., LU K., HUANG W.Q., LÜ Z.H., ZHOU C.M., YU S.C., GAO C.J. High efficient removal of dyes from aqueous solution through nanofiltration using diethanolamine-modified polyamide thin-film composite membrane.Separation and Purification Technology, 173, 143, 2017

3. BILINSKA L., GMUREK M., LEDAKOWICZ S. Textile wastewater treatment by AOPs for brine reuse. Process Safety and Environmental Protection, 109, 428, 2017.

4. BILIŃSKA L., GMUREK M., LEDAKOWICZ S. Comparison between industrial and simulated textile wastewater treatment by AOPs- Biodegradability, toxicity and cost assessment. Chemical Engineering Journal, 306, 559, 2016.

5. PAZ A., CARBAllO J., PEREZ M.J., DOMINGUEZ J.M. Biological treatment of model dyes and textile wastewaters.Chemosphere, 181, 177, 2017.

6. YASEEN D.A.., SCHOLZ M. Comparison of experimental ponds for the treatment of dye wastewater under controlled and semi-natural conditions.Environ Sci Pollut Res, 24, 16040, 2017.

7. LOMP K.M., MENARD D., BARBEAU B.,The influence of iron oxide nanoparticles upon the adsorption of organic matter on magnetic powdered activated carbon.Water Research, 123, 39, 2017.

8. KAZAK O., EKER Y.R., BINGOL H., TOR A. Novel preparation of activated carbon by cold oxygen plasma treatment combined with pyrolysis.Chemical Engineering Journal, 325, 575, 2017.
9. WANG F. Novel high performance magnetic activated carbon for phenol removal,equilibrium, kinetics and thermodynamics.J Porous Mater, 24, 1317, 2017.

10. GAO X.M., ZHANG Y., DAI Y., FU F. High-performance magnetic carbon materials in dye removal from aqueous solutions.Journal of Solid State Chemistry, 239, $273,2016$.

11. OCHIR N.B., SHIM W.G., BALATHANIGAIMANI M.S., MOON H. Highly porous activated carbons prepared from carbon rich Mongolian anthracite by direct $\mathrm{NaOH}$ activation.Applied Surface Science, 379 , 337, 2016.

12. LORENZO N.F., FUENTE E., RUIZ I.S., RUIZ B., KOH activated carbon from conventional and microwave heating system of a macroalgae waste from the agar-agar industry. Fuel Process. Technol, 121, 31, 2014.

13. GONSALVESH L., MARINOVS.P., GRRGLEWICZ G., CARLEER R., YPERMAN J. Preparation,characterization and application of polystyrene based activated carbons for $\mathrm{Ni}$ (II) removal from aqueous solution.Fuel Processing Technology, 149, 85, 2016.

14. BAEK J., LEE H.M., ROH J.S., LEE H.S., KANG H.S., KIM B.J. Studies on preparation and applications of polymeric precursor-based activated hard carbons: I. Activation mechanism and microstructure analyses. Microporous and Mesoporous Materials, 219, 264, 2016.

15. LI C., CHEN N., ZHAO Y.N., LI R., FENG C.P. Polypyrrole-grafted peanut shell biological carbon as a potential sorbent for fluoride removal: Sorption capability and mechanism. Chemosphere, $163,89,2016$.

16. KHOSRAVI R., AZIZIA., GHAEDRAHMATI R., GUPTA V.K., AGARWAL S. Adsorption of gold from cyanide leaching solution onto activated carbon originating from coconut shell-Optimization, kinetics and equilibrium studies, Journal of Industrial and Engineering Chemistrz, 54, 471, 2017.

17. ZHANG G., SHI L., ZHANG Y.F., WEI D., YAN T., WEI Q., DU B. Aerobic granular sludge-derived activated carbon:mineral acid modification and superior dye adsorption capacity.RSC Adv. 5, 25286, 2015.

18. ZAHAR M.S.M., KUSIN F.M., MUHAMMAD S.N. Adsorption of manganese in aqueous solution by steel slag. Procedia Environmental Sciences, 30, 150, 2015.

19. OOI C.H., CHEAH W.K., SIM Y.L., PUNG S.Y., YEOH F.Y. Conversion and characterization of activated carbon fiber derived from palm empty fruit bunch waste and its kinetic study on urea adsorption.Journal of Environmental Management, 197, 205, 2017.

20. CARA I.G., RUSU B.G., RAUS L., JITAREANU G. Sorption potential of alkaline treated straw and a soil for sulfonylurea herbicide removal from aqueous solutions: An environmental management strategy.Chemosphere, 186, 366, 2017.

21. GAO X.M., DAI Y., ZHANG Y., FU F. Effective adsorption of phenolic compound from aqueous solutions on activated semi coke. Journal of Physics and Chemistry of Solids, 102, 150, 2017. 